\title{
An Integrated Structural Equation Model of eHealth Behavioral Intention
}

\author{
Gayle Prybutok, University of North Texas, Denton, USA \\ Anh Viet Ta, University of Nebraska Omaha, Omaha, USA \\ Xiaotong Liu, University of Wisconsin Platteville, Platteville, USA \\ Victor Prybutok, University of North Texas, Denton, USA
}

\begin{abstract}
eHealth offers promising tools and services to manage and improve the quality of health as well as the potential to provide accessible health information all over the world. The relatively low adoption rates among eHealth users motivates us to develop an integrated model to explain the learning process and provide essential antecedents of eHealth behavioral intention. The integrated model is empirically tested by using different structural equation modeling (SEM) methods, including partial least squares SEM (PLS-SEM), PLSc, and covariance-based SEM (CB-SEM). The model successfully explains the learning process and provides essential antecedents of eHealth behavioral intention. The findings support the interplay of social, cognitive, and personal factors that impact 18-30-year-old users' learning process related to eHealth behavioral intention. The results empirically show that these three types of SEM techniques provide consistent results with respect to path coefficients and coefficients of determination. The findings indicate that CB-SEM and PLS-SEM provide adverse consequences of interaction-term path coefficients.
\end{abstract}

\section{KEYWORDS}

Covariance-based Structural Equation Model, eHealth Behavioral Intention, Partial Least Squares, Social Cognitive Theory, Structural Equation Modeling

\section{INTRODUCTION}

The acquisition of real-time, on-demand health information from traditional health channels (e.g., hospitals, clinics, and primary care physicians) is costly and inconvenient for most health information and service seekers (Zhang et al., 2017). To fulfill health information needs in a timely and convenient manner, many users are seeking health information and services through other channels. Internet venues offer real-time accessibility for young users to immediately search for health information, exchange health information effectively, and can simultaneously fulfill the needs of a large number of users (Prybutok et al., 2014). In general, online health information has great potential to boost the quality of personal healthcare and the use of preventive health behaviors by users (Hsieh, 2016).

According to the World Health Organization (WHO), eHealth is a relatively new term reflecting the adoption of "information and communication technologies (ICT) for health" (WHO, 2017). In other words, eHealth involves the delivery of health-related information and services through the Internet and related technologies (Prybutok, 2014). Users can access the Internet to learn more about their health issues, obtain a basic knowledge of their diseases and treatments, and get relevant 
and reliable health information when making health-related decisions (Zhang et al., 2017). Many health practitioners build online health platforms that store patients' health information, such as health insurance and electronic medical records (EMR). The online platform allows more efficient interactions among health providers and users (Hsieh, 2016). Zhang et al. (2017) showed that eHealth improves the user's health status by providing effective professional and social support to improve personal health management and decision making. eHealth provides an effective venue for timely and on-demand access to online health resources with little effort. WHO (2016) showed that eHealth is a useful tool and service to manage and improve the quality of healthcare and is a promising solution for making health information accessible across the world. Individuals and health practitioners use online health venues and services to complement traditional face to face and print health information channels and to encourage healthy lifestyles or proactive health behaviors (Prybutok et al., 2017). Thus, eHealth can benefit both individuals and society as a whole (Yi et al., 2013).

Although eHealth is a promising tool and a future-oriented source of health information and communication, online health information venues still have a relatively low visit rate (Zhang et al., 2017). The low intention to use eHealth and the paucity of the related literature lead to the necessity to build an integrated model to examine how 18-30-year-old users' social, cognitive, and personal factors influence eHealth Behavioral Intention. From a practical standpoint, understanding why users adopt eHealth and how such adoption is incorporated into their decision-making process allows healthcare practitioners to develop effective promotional strategies to maximize user adoption and improve the positive impact of eHealth on personal health management. Furthermore, from the social cognitive perspective, this study expects that users' eHealth behaviors related to online health information and services will be a function of the users' cognitive judgment about their ability to adopt and implement activities recommended by online health information sources and services.

This study is the first to simultaneously examine the effects of a personal motivational factor (Health Information Orientation), a cognitive factor (Attitude toward eHealth), a personal skill factor (eHealth Literacy), a personal behavioral factor (Online Health Behavior), and a social factor (Need for Online Social Interaction) on the eHealth Behavioral Intention of 18-30-year-old users. The constructs, definitions, and sources are presented in Table 1.

The eHealth literature suggests that disparate factors drive eHealth Behavioral Intention with respect to the population of 18-30-year-olds, who are the most active group of Internet users (Pew Research Center, 2017). Guided by well-established theories including Social Cognitive Theory (SCT) (Bandura, 1986), the Theory of Reasoned Action (TRA) (Ajzen \& Fishbein, 1980), and the Theory of Planned Behavior (TPB) (Ajzen, 1985), the authors develop a new model capturing the most important antecedents of eHealth Behavioral Intention for this population. SCT considers the social cognitive determinants together with the personal determinants and suggests that learned experiences, social environment, and behavioral capability are the main driving factors of the learning process (Bandura, 1998). TRA and TPB provide the theoretical foundation for the proposed relationships among Health Information Orientation, Attitude toward eHealth, eHealth Literacy, and eHealth Behavioral Intention. The model not only substantially contributes to the eHealth literature but also has value for health providers and educators. Understanding the health-related behaviors of 18-30-year-old users enables health information professionals and eHealth system administrators to improve users' personal health management and the use of preventive health measures delivered via the Internet to this user population.

To empirically test the research model, the authors surveyed 3,064 18-30-year-old college students enrolled at a state university in the southwestern area of the United States and, after data cleaning, analyzed 1,432 valid responses using partial least squares structural equation modeling (PLS-SEM), PLSc, and covariance-based structural equation modeling (CB-SEM) methods. While the PLS-SEM approach seeks to maximize the explained variance value $\mathrm{R}^{2}$ of the endogenous (dependent) latent constructs using a regression-based ordinary least squares estimation, the CB-SEM approach uses a maximum likelihood estimation to reproduce the theoretical covariance matrix (Hair, Hult, Ringle, 
Table 1. Constructs, definitions and sources

\begin{tabular}{|l|l|l|}
\hline \multicolumn{1}{|c|}{ Construct } & \multicolumn{1}{|c|}{ Definition } & \multicolumn{1}{c|}{ Source } \\
\hline Health Information Orientation & $\begin{array}{l}\text { the extent to which an individual's attitudes and } \\
\text { motivations are directed toward maintaining a } \\
\text { healthy lifestyle. }\end{array}$ & Dutta-Bergman (2003) \\
\hline Attitude toward eHealth & $\begin{array}{l}\text { the individual's internal willingness and ability to } \\
\text { use eHealth or Internet-based health information } \\
\text { sources. }\end{array}$ & $\begin{array}{l}\text { Marton (2003) and Richards et } \\
\text { al. (2005) }\end{array}$ \\
\hline eHealth Literacy & $\begin{array}{l}\text { the extent to which an individual has the skills } \\
\text { required to find, evaluate, and appropriately apply } \\
\text { health information drawn from electronic sources } \\
\text { to solve a health problem. }\end{array}$ & Norman and Skinner (2006) \\
\hline Online Health Behavior & $\begin{array}{l}\text { the extent to which an individual uses digital } \\
\text { information and technology to develop and } \\
\text { promote a healthy lifestyle. }\end{array}$ & $\begin{array}{l}\text { adapted from Weaver et al. } \\
\text { (2010) and Escoffery et al. } \\
\text { (2005) }\end{array}$ \\
\hline $\begin{array}{l}\text { Need for Online Social } \\
\text { Interaction }\end{array}$ & $\begin{array}{l}\text { an individual's desire to explore and communicate } \\
\text { with others via the Internet. }\end{array}$ & $\begin{array}{l}\text { contextualized from Haridakis } \\
\text { and Hanson (2009) }\end{array}$ \\
\hline eHealth Behavioral Intention & $\begin{array}{l}\text { the user's intention, based on health information } \\
\text { found on the Internet, to implement a behavior to } \\
\text { prevent a disease or manage a potential health risk. }\end{array}$ & $\begin{array}{l}\text { Hu and Sundar (2010) and } \\
\text { Prybutok (2014) }\end{array}$ \\
\hline
\end{tabular}

\& Sarstedt, 2016). Behavioral and business research contains numerous applications of CB-SEM and PLS-SEM. Recent criticism of PLS-SEM within the operations management literature (e.g., Guide and Ketokivi, 2015; Rönkkö et al., 2016; Ronkko and Evermann, 2013) resulted in many researchers publishing support for PLS. This study sheds light on this argument by testing, in the context of an eHealth application, the consistency of hypothesis testing results, R squares, and goodness of fit indices, when applying different SEM approaches. Also, responding to Ringle et al.'s (2012) call that researchers should use other statistical fit indices besides $\mathrm{R}^{2}$ for a better evaluation of the overall model fit in PLS-SEM models, this study is the first to compare the model fit indices of CB, PLS-SEM, and PLSc on an identical model using survey data. The study also addresses Hair et al.'s (2017) call for future research by investigating the performance of SEM methods when using a complex model design with additional interaction terms.

\section{INTERNET AS A HEALTH INFORMATION CHANNEL}

Advanced technology and the increasing demand for real-time information facilitated the expansion of online health venues, which, in turn, lead to changes in health behavior. The worldwide shortage of health workers like doctors, nurses, laboratory technicians, and midwives reached almost 7.2 million in 2017 and is expected to reach 12.9 million by 2035 (WHO, 2016, 2018). eHealth is one possible solution for the shortage because it provides potential tools to access health information, change health behaviors, and prevent the spread of diseases (WHO, 2016). Providing online health information and services became a new trend in many hospitals, clinics, and health service organizations. Thus, health practitioners and individuals followed the trend toward adopting eHealth (Prybutok et al., 2017). Overall, eHealth is convenient for health organizations, practitioners, and individuals. The availability and potential value of eHealth to individuals and healthcare providers have stimulated current research aimed at improving the understanding of the factors that motivate health practitioners and individuals to develop eHealth Behavioral Intention.

According to Social Learning Theory proposed by Bandura (1969), media influences, social interactions, and daily experiences are the main ways for people to observe and learn. The Internet 
and social media represent new forms of media communication that can influence users, foster online social interactions, and change information-seeking behaviors. With the development of the Internet and its associated social media sites, people can observe, interact, and learn anytime from a convenient and accessible location. The ways people access health information and communicate with healthcare providers have also been significantly changed by the Internet. Eng et al.'s (1999) study of interactive health communication emphasized the role of the Internet as a mediator for the relationship between personal interactions and health information. Internet users can easily contact others who are afflicted with similar illnesses, gather health information to manage their own health, and make more informed health-related decisions (Suggs, 2006). The Internet and social media are promising tools to spread important healthcare information to the public and improve eHealth literacy. In other words, they provide the opportunity for online users to find, understand, and appropriately apply health information to solve personal health problems, and, ultimately, develop eHealth Behavioral Intention.

Statistics indicated that 99 percent of 18-30-year-olds and only 64 percent of people 65 years old and above in the U.S. used the Internet in 2016 (Pew Research Center, 2017). Consequently, the group of 18-30-year-olds is more likely to encounter healthcare information on the Internet and other social media platforms than any other group (Liu, 2010). Information Encountering, described by Erdelez (1999), suggested that an individual can acquire unexpected and useful information while he or she was not actively searching for it, and was engaged in another activity. Kelly et al. (2009) applied Information Encountering to the eHealth context and confirmed that although some Internet users do not actively search for health information, they can obtain a substantial amount of health information through a chance encounter online while seeking information for another person or purpose. In addition, the Centers for Disease Control and Prevention (CDC) (2011) published The Social Media Toolkit in 2011, in which they provided guidelines for health educators on the use of the Internet and social media to communicate important health information to specific user groups. The CDC emphasized the role of social media as an effective health information channel that can support health educators in their efforts to provide timely and accurate health information to the public.

eHealth saves health providers and educators a tremendous amount of time and improves communication among users and between patients and their healthcare providers. Understanding and enhancing eHealth information access and exchange for 18-30-year-olds are important in promoting the personal health behaviors of this age group, particularly in the effort to reduce the incidence of health concerns highly prevalent in this population. These include such risks as sexually transmitted diseases (STD) (Prybutok, 2013), the increase in vaping (McMillen et al. 2015; Unger et al. 2016), increasing use of marijuana (Macleod et al., 2004), associated health risks and opiate addiction (Jones, 2013; Lankenau et al., 2012; McCabe et al. 2005; Zibbell et al. 2015). To improve the delivery of important health information to this group of Internet and social media users, this study developed and tested an eHealth related model to investigate crucial factors associated with the development of eHealth Behavioral Intention among 18-30-year-olds.

\section{THEORETICAL BACKGROUND AND HYPOTHESES DEVELOPMENT}

Many studies have discussed healthcare information seeking behaviors. For example, Godin and Kok (1996) used the TPB model to explain and predict different health-related categories such as HIV/AIDS, Oral hygiene, and addictive behaviors. Han et al. (2012) examined the effects of social and psychological factors in the context of an online breast cancer support group. Noh et al. (2009) investigated the information needs and information seeking behavior among cervical cancer patients. In addition, Kim and Yoon (2012) studied the usefulness of online health forum platforms for providing health information among Korean immigrants. This study generalizes the existing research in a broader context, which is the Internet and healthcare information in general and does not focus on any specific diseases or a single health issue. This study also focuses on the population of active Internet users who are 18-30 years old by investigating the influence of the interplay of social, 
cognitive, and personal factors on transforming individual healthcare behaviors. In short, based on the theories of TRA, TPB, and SCT, the current study develops and tests a new model to investigate the factors that drive behavioral intention in 18-30-year-olds who use Internet sources as channels for health information and communication.

This study uses Bandura's (1986) Social Cognitive Theory (SCT) as the primary theoretical foundation. SCT, which originates from Social Learning Theory (SLT), (Bandura 1969), stated that learning is a cognitive process in which individuals observe the behaviors of others in their social environments and, subsequently, learn these new behaviors. Bandura (1986) used SCT to explain how technological changes transform individuals' behaviors through the interplay of social, cognitive, and personal factors. Thus, the theory was used to explain how social, cognitive, or personal factors influence the learning process. Based on SCT, this study proposes five crucial factors in the proposed eHealth Behavioral Intention Model. Health Information Orientation, eHealth Literacy, and Online Health Behavior represent three dimensions of personal factors, including motivation, skill, and behavior, respectively. In addition, Attitude toward eHealth and Need for Online Social Interaction represent cognitive and social factors, respectively. The authors selected these constructs by considering the interacting effects of social, cognitive, and personal factors on eHealth Behavioral Intention in this population.

A number of prior studies (e.g., Hu \& Shyam Sundar, 2010; Marton, 2003; Norman \& Skinner, 2006; Richards et al., 2005) have examined factors, identified in specific age groups, that correlate with the use of the Internet and social media to find, evaluate, and appropriately implement health information. This study has drawn from the literature to build constructs of the proposed eHealth model.

The Internet is an important source of health information for people of all ages, and those who are committed to maintaining a healthy lifestyle are more likely to use the Internet to obtain health information and services related to their own health concerns. People use eHealth behaviors to search for health information and monitor their health conditions. In other words, eHealth adoption is relevant to their motivation to seek health information. Thus, the construct Health Information Orientation, which is the willingness and motivation to live a healthy lifestyle (Cho et al., 2014), is considered the initial driving factor of eHealth Behavioral Intention. According to SCT, during the process of adopting eHealth, users gradually develop an Attitude towards eHealth (a cognitive factor). In addition, this study deems the Theory of Reasoned Action (TRA) (Ajzen \& Fishbein, 1980) and the Theory of Planned Behavior (TPB) (Ajzen, 1985) as theoretical backgrounds against which to examine the cognitive decision-making process that results in Behavioral Intention among 18-30-yearold eHealth users. According to TRA and TPB, beliefs lead to attitudes. Using this rationale, Health Information Orientation (the way that an individual's motivations and attitudes are directed toward leading a healthy lifestyle) leads to Attitude toward eHealth.

Hypothesis 1a: Health Information Orientation positively relates to Attitude toward eHealth.

According to SCT, a personal motivational factor, Health Information Orientation, triggers an individual to acquire the necessary competence to accurately find and appropriately apply the health information they find on the Internet (Cho et al., 2014). This ability to apply the knowledge learned refers to eHealth Literacy, another important driving factor in the proposed model. People who have a predisposition to maintain their health are more likely to learn and develop the necessary skills to solve their own simple health issues. Based on these arguments, this study proposes that an individual's Health Information Orientation also relates to eHealth Literacy (Norman \& Skinner, 2006).

Hypothesis 1b: Health Information Orientation positively relates to eHealth Literacy. 
$\mathrm{Hu}$ and Sundar's (2010) study showed that behavioral intention is the degree to which an individual intends to adopt a new behavior based on both how he views his ability to be successful at the behavior and by how he thinks he will be evaluated by others if he performs the new behavior. In this research context, this behavior would be a health management or disease prevention behavior motivated by eHealth sources. Considering Moorman and Matulich's (1993) study that defined Health Information Orientation as a motivation to participate in preventive health behaviors. Cho et al. (2014) argued that the higher the level of Health Information Orientation, the greater the possibility for the individual to seek information from various sources. This study establishes a potential relationship between Health Information Orientation and eHealth Behavioral Intention.

Hypothesis 1c: Health Information Orientation positively relates to eHealth Behavioral Intention.

TRA and TPB show that beliefs lead to attitudes, which, in turn, changes users' intention and behavior. Thus, in this eHealth context, Attitude toward eHealth should lead to changes in eHealth Behavioral Intention. However, users must develop the necessary skills to competently understand and appropriately apply health information found online before developing eHealth Behavioral Intention. In other words, people who are willing and able to use eHealth sources are more likely to achieve eHealth Literacy. It is reasonable that eHealth Literacy mediates the relationship between Attitude toward eHealth and eHealth Behavioral Intention.

Hypothesis 2: Attitude toward eHealth positively relates to eHealth Literacy.

It is reasonable to suggest that when a user can more competently find, evaluate and appropriately apply health information from online health resources, it is more likely that the user will have the Behavioral Intention to adopt eHealth. Paek and Hove (2012) proposed that perceived social norms play an important role in eHealth Literacy. The Theory of Reasoned Action (Ajzen \& Fishbein, 1980; Fishbein \& Ajzen, 1977) and the Theory of Planned Behavior (Ajzen, 1985) explained that social norms are among the main factors affecting an individual's intention to accept new technology. Based on these studies, the higher an individual's eHealth Literacy (a personal skill factor), the higher the possibility that he or she will change the health-related behavior as recommended by eHealth sources. In other words, an individual's eHealth Literacy positively relates to the individual's eHealth Behavioral Intention.

Hypothesis 3: eHealth Literacy positively relates to eHealth Behavioral Intention.

In addition to social, cognitive and eHealth Literacy (a personal skill factor) discussed above, this study examined the role of Online Health Behavior (a personal behavioral factor) in the development of eHealth Behavioral Intention. Online Health Behavior (a personal behavioral factor), contextualized from Weaver et al.'s (2010) and Escoffery et al.'s (2005) studies, is an individual's desire to use the Internet to develop and promote a healthy lifestyle. It is necessary to emphasize the association between Online Health Behavior and eHealth Behavioral Intention. The individual who has more frequent Online Health Behavior will be more likely to adopt and carry out a more effective health behavior based on information from eHealth sources.

Hypothesis 4: Online Health Behavior positively relates to eHealth Behavioral Intention.

With respect to the relationship between Health Information Orientation and eHealth Behavioral Intention, and between Attitude towards eHealth and eHealth Literacy, Need for Online Social Interaction (a social factor) may influence the individual's motivation to find and exchange relevant 
health information and the skills required to evaluate and appropriately apply the health information found on the Internet. These relationships imply the potential role of the Need for Online Social Interaction in moderating the relationship between Health Information Orientation and eHealth Behavioral Intention and between Attitude towards eHealth and eHealth Literacy. According to Haridakis and Hanson (2009), Need for Online Social Interaction is an individual's desire to discover and connect with others via the Internet. The greater the Need for Online Social Interaction, the more frequently an individual participates in discussions or meets new people online. Social media sites such as Facebook and YouTube provide environments in which people not only communicate with but also learn from one another. An individual's need to interact socially on the Internet and social media increases the opportunity to develop a positive opinion (Attitude toward eHealth) about Internetbased health information, as well as to evaluate and appropriately apply the health information found and exchanged on the Internet.

Hypothesis 5a: Need for Online Social Interaction strengthens the positive relationship between Attitude toward eHealth and eHealth Literacy.

Reinforcement Theory (Atkin, 1973, 1985) showed that people prefer to trust information that supports their existing beliefs. Thus, individuals who become familiar with exchanging health information on the Internet develop faith in the information, especially when the information is consistent with what they already know. Once they build confidence in the accuracy and reliability of the information, they are more likely to adopt the health behaviors presented, which results in eHealth Behavioral Intention. In addition, people who have a greater Health Information Orientation will be more likely to view and communicate with other online users to acquire and exchange health-related information. This online interaction can subconsciously change an individual's behavior without any guidance (Chartrand \& Bargh, 1999). Therefore, the Need for Online Social Interaction will improve the chance that an individual, whose has a high degree of Health Information Orientation, develops the Behavioral Intention to acquire and apply eHealth information to address a health-related issue.

Hypothesis 5b: Need for Online Social Interaction strengthens the positive relationship between Health Information Orientation and eHealth Behavioral Intention

\section{RESEARCH METHOD AND DATA ANALYSIS}

\subsection{Sample and Data Collection}

Figure 1 presents the proposed model, which shows the relationship among constructs including Attitude toward eHealth, Health Information Orientation, eHealth Literacy, Online Health Behavior, Need for Online Social Interaction, and eHealth Behavioral Intention. The questionnaires were contextualized from validated surveys published in academic journals. The online survey was sent to 18-30-year-old college students at a Southwestern university to test the hypotheses. Also, the survey was sent to mutually exclusive courses to avoid overlapped data. For example, the authors sent the survey to different sections of the same course as well as to upper-level courses that required the lower level courses as prerequisites. The questionnaires also asked participants not to complete the survey if they have done it in other courses. Faculty agreed to offer the students who took the survey extra credit for participating while offering non-participants or the few that had taken the survey for another course an alternate extra credit opportunity. The survey was distributed to 3,064 students via Qualtrics (Qualtrics, 2005), a well-known online survey platform, over a two-week period. The authors collected 2,008 responses (65.5\% response rate). After removing incomplete responses, responses where respondents gave the same answer for every question, or responses from those 


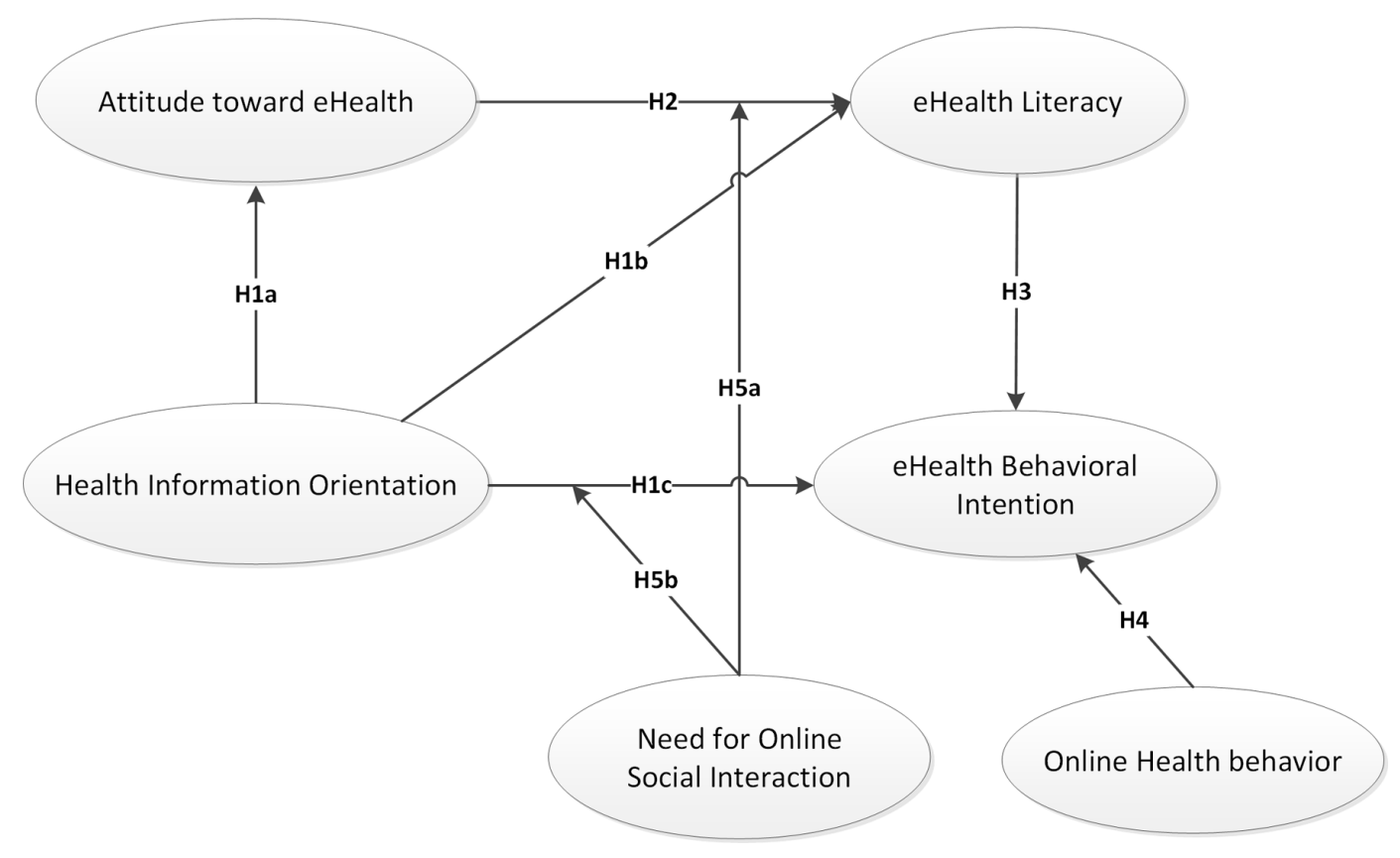

outside of the targeted age range, 1,432 usable responses were used to analyze the proposed model. The demographic analysis illustrates that the sample had $47.7 \%$ females and $52.3 \%$ males, indicating a close gender split of this university convenience sample.

\subsection{Structural Equation Modeling}

Structural equation modeling (SEM) is a powerful multivariate analytical method used to analyze the inter-correlations among observed variables and latent constructs in complex models. The two primary SEM approaches are covariance-based SEM (CB-SEM), developed by Jöreskog (1973), and partial least squares path modeling SEM (PLS-SEM), developed by Wold (1974). Although PLSSEM is considered a "silver bullet" multivariate analysis method to estimate models in marketing, management, management information systems (MIS), and many other research areas (e.g., Hair et al. 2017; Hair et al. 2011; Ringle et al. 2012), several researchers have questioned the legitimacy of this method (e.g., Guide \& Ketokivi, 2015; Ronkko \& Evermann, 2013; Rönkkö et al., 2016). For example, researchers, who oppose the use of PLS-SEM, predominantly stated that either the estimated parameter of PLS-SEM is not consistent, or the method lacks model fit indices. As a result of the efforts to improve PLS-SEM, Plesk (Dijkstra \& Henseler, 2015), in which c stands for consistency, was introduced to improve the consistency issues in the conventional PLS-SEM method. Although several studies empirically compare the performance of CB-SEM and PLS-SEM (Astrachan et al., 2014), and PLS and PLSc (Gelhard \& Delft, 2016), no study simultaneously examines the performance of the three methods in an identical research context. This study adds value to the rich SEM literature by empirically testing the same eHealth related model using the three SEM methods. This study compares the performance of each SEM method by evaluating the results of path coefficients, coefficients of determination, and model fit indices. In addition, this research investigates the moderating effect of Need for Online Social Interaction on the path coefficients of the proposed model. 


\subsection{Model Assessment}

This study tests the hypotheses by using PLS-SEM, PLSc, and CB-SEM methods. While SmartPLS 3.0 is used to conduct the PLS-SEM and PLSc methods, IBM SPSS AMOS is used for the CB-SEM analysis. Olkin and Finn's (1995) standard error estimation was used to investigate the statistical difference of R squares of exogenous latent constructs collected from different SEM methods. Several tests were conducted with the raw data to confirm the reliability and validity of the latent indicators. According to Table 2, the results of composite reliability (Werts et al., 1974) and Cronbach's alpha (Cronbach, 1951) for all latent constructs exceed the suggested threshold of 0.8 and 0.7 respectively (Nunnally \& Bernstein, 1994). The results indicate that the reliability of the indicator variables is acceptable. Results in Table 2 shows that the correlation between eHealth Literacy and Attitude toward eHealth is relatively high. It is intuitive that the two constructs are naturally correlated because respondents who have a high level of eHealth Literacy are more likely to have a positive Attitude toward eHealth. Although the correlation of 0.625 is high, it is well below the square root of the AVE of eHealth Literacy (0.831) and Attitude toward eHealth (0.873). Thus, the Fornell \& Larcker (1981) criteria suggested that the high correlation does not affect the discriminant validity. The multicollinearity related issues are also addressed because the variance inflation factors (VIF) were below the threshold of 3 (Hair et al., 2011).

Component factor analysis was used to test the convergence validity of indicator variables. The factor loadings of all items are higher than the threshold of 0.7, and the cross-loading values are lower than the cutoff value of 0.4 (Hair et al., 2016). In Table 3, the cross-loading values lower than 0.4 are left blank because the authors chose to suppress coefficients with absolute values below 0.4 to maintain the simplicity of the presentation. The convergence validity at the construct level was satisfied because the average variance extracted (AVE) of each construct is higher than 0.5 (Fornell $\&$ Larcker, 1981). The discriminant validity was also valid since the square root of the AVE of each construct is higher than the highest correlation of the corresponding construct (Fornell \& Larcker, 1981).

\subsection{Structural Model Results}

According to Figure 2, all hypotheses, except the hypotheses of interaction terms, are supported by the three SEM methods. All path coefficients are significant at the 0.001 level. The values of PLSc's path coefficients, except the path from eHealth Literacy to eHealth Behavioral Intention and from Online Health Behavior to eHealth Behavioral Intention, are in-between the values of PLS-SEM's

Table 2. Reliability and construct validity

\begin{tabular}{|c|c|c|c|c|c|}
\hline & $\begin{array}{c}\text { Health } \\
\text { Information } \\
\text { Orientation }\end{array}$ & eHealth Literacy & $\begin{array}{l}\text { Attitude } \\
\text { toward } \\
\text { eHealth }\end{array}$ & $\begin{array}{c}\text { Online } \\
\text { Health } \\
\text { Behavior }\end{array}$ & $\begin{array}{c}\text { eHealth } \\
\text { Behavioral } \\
\text { Intention }\end{array}$ \\
\hline Cronbach's Alpha & 0.918 & 0.925 & 0.896 & 0.835 & 0.838 \\
\hline Composite Reliability & 0.932 & 0.94 & 0.928 & 0.901 & 0.903 \\
\hline AVE & 0.606 & 0.691 & 0.762 & 0.752 & 0.756 \\
\hline Health Information Orientation & 0.778 & & & & \\
\hline eHealth Literacy & 0.440 & 0.831 & & & \\
\hline Attitude toward eHealth & 0.462 & 0.625 & 0.873 & & \\
\hline Online Health Behavior & 0.271 & 0.149 & 0.184 & 0.867 & \\
\hline eHealth Behavioral Intention & 0.419 & 0.412 & 0.461 & 0.205 & 0.869 \\
\hline
\end{tabular}

* The bold diagonal values are the square root of AVEs and the off-diagonal elements are correlations between latent variables 
Table 3. Principal component analysis and model assessment of the dataset

\begin{tabular}{|c|c|c|c|c|c|}
\hline & $\begin{array}{c}\text { Health } \\
\text { Information } \\
\text { Orientation }\end{array}$ & $\begin{array}{l}\text { eHealth } \\
\text { Literacy }\end{array}$ & $\begin{array}{c}\text { Attitude toward } \\
\text { eHealth }\end{array}$ & $\begin{array}{l}\text { Online Health } \\
\text { Behavior }\end{array}$ & $\begin{array}{c}\text { eHealth } \\
\text { Behavioral } \\
\text { Intention }\end{array}$ \\
\hline HIO1 & 0.773 & & & & \\
\hline $\mathrm{HIO} 2$ & 0.814 & & & & \\
\hline $\mathrm{HIO} 3$ & 0.773 & & & & \\
\hline $\mathrm{HIO} 4$ & 0.727 & & & & \\
\hline HIO5 & 0.765 & & & & \\
\hline HIO6 & 0.806 & & & & \\
\hline HIO7 & 0.666 & & & & \\
\hline HIO8 & 0.713 & & & & \\
\hline HIO9 & 0.608 & & & & \\
\hline eHL1 & & 0.755 & & & \\
\hline eHL2 & & 0.775 & & & \\
\hline eHL3 & & 0.800 & & & \\
\hline eHL4 & & 0.815 & & & \\
\hline eHL5 & & 0.785 & & & \\
\hline eHL6 & & 0.779 & & & \\
\hline eHL7 & & 0.736 & & & \\
\hline ATeH1 & & & 0.738 & & \\
\hline $\mathrm{ATeH} 2$ & & & 0.764 & & \\
\hline $\mathrm{ATeH} 3$ & & & 0.772 & & \\
\hline $\mathrm{ATeH} 4$ & & & 0.773 & & \\
\hline OHB1 & & & & 0.867 & \\
\hline OHB2 & & & & 0.878 & \\
\hline OHB3 & & & & 0.808 & \\
\hline eHBI2 & & & & & 0.683 \\
\hline eHBI3 & & & & & 0.853 \\
\hline eHBI4 & & & & & 0.845 \\
\hline
\end{tabular}

HIO: Health Information Orientation, ATeH: Attitude toward eHealth, eHL: eHealth Literacy, OHB: Online Health Behavior, eHBI: eHealth Behavioral Intention.

and CB-SEM's corresponding coefficients. For example, the PLSc's path coefficient between Health Information Orientation and Attitude toward eHealth is 0.516, which is in-between the PLS-SEM's value of 0.470 and CB-SEM's value of 0.589 . According to the analysis of path coefficients of each SEM method in Table 4, the corresponding path coefficients between PLS and PLSc are not significantly different at the 0.05 level. Four corresponding path coefficients between PLS and CBSEM, and three between PLSc and CB-SEM are significantly different at the 0.05 level.

According to the results of variance explained in Table 4, three methods produce different and relatively high values of $\mathrm{R}$ squares in the context of eHealth related models. The values of PLSc's $\mathrm{R}$ squares of Attitude toward eHealth, eHealth Literacy, and eHealth Behavioral Intention are in- 
between the values of PLS and CB methods. For example, the R square of eHealth Literacy from PLSc method is 49.5\%, while the corresponding PLS's and CB's R square is $42.4 \%$ and $57.9 \%$ respectively. All R squares produced by PLSc and PLS methods are significantly different. For the model using the CB-SEM method, the results of the measurement model indicate a good fit (NFI = $0.999, \mathrm{CFI}=0.999, \mathrm{RMR}=0.005$, RMSEA $=0.021$, PCLOSE $=.866$, GFI $=.999$, AGFI $=.993$, PGFI =.133). The goodness of model fit is also supported by PLS-SEM (SRMR $=0.052$, NFI $=$ $0.87)$ and PLSc $($ SRMR $=0.048, \mathrm{NFI}=0.84)$. The analysis of interaction terms, Table 6 , indicates the inconsistency among the three SEM methods. The hypothesis 5a was marginally supported by CB-SEM, while rejected by PLS-SEM and PLSc. Hypothesis 5b was supported by PLS-SEM and marginally supported by PLSc, while rejected by CB-SEM.

\section{DISCUSSION}

The proposed theoretical model provides an important contribution to the literature on eHealth education and online health informatics. The supported hypotheses, high $\mathrm{R}^{2}$, and global fit indices support the appropriateness of the proposed model to understand the decision-making process of 18-30-year-old health information seekers. The results show that Health Information Orientation, Attitude toward eHealth, and Online Health Behavior are important antecedents of eHealth Literacy and eHealth Behavioral Intention for the college student sample. The results support the use of social cognitive theory (SCT) as a theoretical background to investigate how the Internet is transforming individuals' behaviors through the complex interactions of social, cognitive, and personal factors. The results show that the interplay of a personal motivational factor (Health Information Orientation), a cognitive factor (Attitude toward eHealth), a personal skill factor (eHealth Literacy), a personal behavioral factor (Online Health Behavior), and a social factor (Need for Online Social Interaction)

Figure 2. PLS-SEM and CB-SEM results

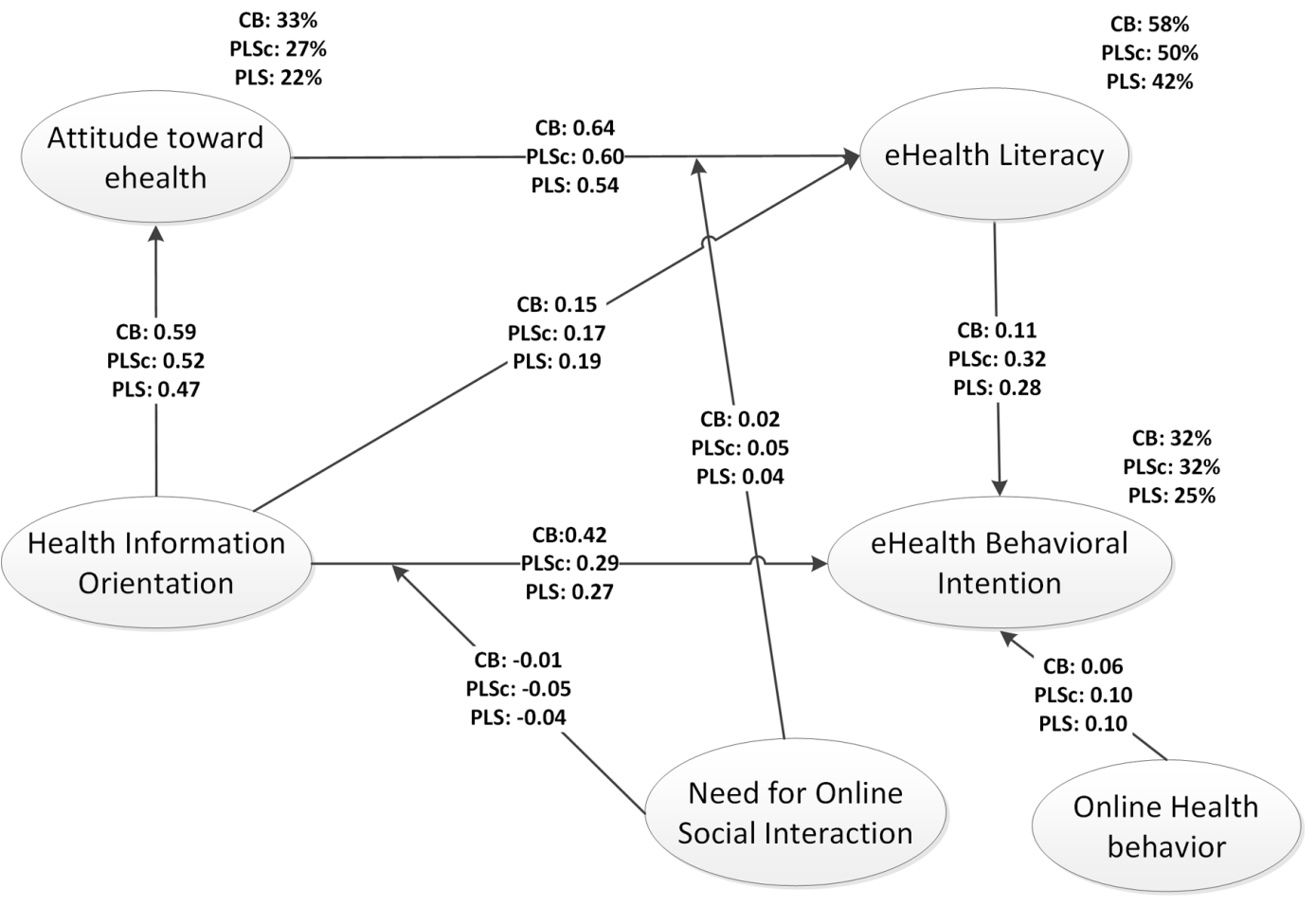


Table 4. Results of path coefficients and variance explained

\begin{tabular}{|l|l|l|l|l|l|l|}
\hline & \multicolumn{1}{|c|}{$\begin{array}{c}\text { Path } \\
\text { Coefficient }\end{array}$} & \multicolumn{1}{|c|}{ SD } & \multicolumn{1}{c|}{$\begin{array}{c}\text { Path } \\
\text { Coefficient }\end{array}$} & \multicolumn{1}{c|}{ SD } & \multicolumn{1}{c|}{$\begin{array}{c}\text { Path } \\
\text { Coefficient }\end{array}$} & \multicolumn{2}{c|}{ CESc } \\
\hline & \multicolumn{2}{|c|}{ PLS-SEM } & \multicolumn{2}{c|}{ PLS } \\
\hline $\mathrm{HIO} \rightarrow \mathrm{ATeH}$ & 0.470 & 0.026 & 0.516 & 0.027 & 0.589 & 0.022 \\
\hline $\mathrm{HIO} \rightarrow \mathrm{eHL}$ & 0.193 & 0.025 & 0.174 & 0.033 & 0.149 & 0.021 \\
\hline $\mathrm{ATeH} \rightarrow \mathrm{eHL}$ & 0.537 & 0.027 & 0.597 & 0.034 & 0.636 & 0.020 \\
\hline $\mathrm{eHL} \rightarrow \mathrm{eHBI}$ & 0.287 & 0.029 & 0.318 & 0.032 & 0.112 & 0.032 \\
\hline $\mathrm{OHB} \rightarrow \mathrm{eHBI}$ & 0.096 & 0.024 & 0.102 & 0.031 & 0.060 & 0.015 \\
\hline $\mathrm{HIO} \rightarrow \mathrm{eHBI}$ & 0.269 & 0.029 & 0.294 & 0.035 & 0.423 & 0.028 \\
\hline & $\mathrm{R} 2$ & SE & R2 & SE & R2 & SE \\
\hline $\mathrm{ATeH}$ & 0.220 & 0.0192 & 0.267 & 0.0199 & 0.327 & 0.0202 \\
\hline $\mathrm{eHL}$ & 0.424 & 0.0197 & 0.495 & 0.0187 & 0.579 & 0.0169 \\
\hline $\mathrm{eHBI}$ & 0.254 & 0.0198 & 0.315 & 0.0202 & 0.317 & 0.0202 \\
\hline
\end{tabular}

*All path coefficient significant at the 0.001 level.

Table 5. Analysis of path coefficients and variance explained

\begin{tabular}{|l|l|l|l|l|l|l|l|l|l|l|l|}
\hline & Change & t-value & p-value & Change & t-value & p-value & Change & t-value & p-value \\
\hline & \multicolumn{3}{|c|}{ PLS vs PLSc } & \multicolumn{3}{c|}{ PLS vs CB } & \multicolumn{3}{c|}{ PLSc vs CB } \\
\hline $\mathrm{HIO} \rightarrow \mathrm{ATeH}$ & -0.046 & 1.228 & 0.220 & -0.119 & 3.495 & 0.000 & -0.073 & 2.097 & 0.036 \\
\hline $\mathrm{HIO} \rightarrow \mathrm{eHL}$ & 0.019 & 0.459 & 0.646 & 0.044 & 1.348 & 0.178 & 0.025 & 0.639 & 0.523 \\
\hline $\mathrm{ATeH} \rightarrow \mathrm{eHL}$ & -0.06 & 1.382 & 0.167 & -0.099 & 2.947 & 0.003 & -0.039 & 0.989 & 0.323 \\
\hline $\mathrm{eHL} \rightarrow \mathrm{eHBI}$ & -0.031 & 0.718 & 0.473 & 0.175 & 4.054 & 0.000 & 0.206 & 4.554 & 0.000 \\
\hline $\mathrm{OHB} \rightarrow \mathrm{eHBI}$ & -0.006 & 0.153 & 0.878 & 0.036 & 1.272 & 0.203 & 0.042 & 1.220 & 0.223 \\
\hline $\mathrm{HIO} \rightarrow \mathrm{eHBI}$ & -0.025 & 0.550 & 0.582 & -0.154 & 3.822 & 0.000 & -0.129 & 2.879 & 0.004 \\
\hline & $\mathrm{R} 2$ & & & $\mathrm{R} 2$ & & & $\mathrm{R} 2$ & & 0.034 \\
\hline $\mathrm{ATeH}$ & -0.047 & 1.700 & 0.089 & -0.107 & 3.841 & 0.000 & -0.060 & 2.117 & 0.034 \\
\hline $\mathrm{eHL}$ & -0.071 & 2.615 & 0.009 & -0.155 & 5.974 & 0.000 & -0.084 & 3.334 & 0.001 \\
\hline $\mathrm{eHBI}$ & -0.061 & 2.157 & 0.031 & -0.063 & 2.228 & 0.026 & -0.002 & 0.070 & 0.944 \\
\hline
\end{tabular}

has an important influence on the 18-30-year-old young adults' eHealth Behavioral Intention from the social cognitive perspective. The SCT illustrates that people's competency includes not only technical skills but also self-confidence in their ability to successfully employ these skills (Bandura, 1988). First, 18-30-year-old adults develop eHealth related capabilities through observations of how others use the Internet as a channel to seek health-related information and services. When these young adults believe they are able to use eHealth resources, they utilize the Internet with the support of learned online health behavior to seek health-related information and services more efficiently to prevent spreading diseases or to make other important health decisions. Later, these eHealth users elevate their intentions to use the Internet as a venue to assist in personal health management or to maintain a healthy lifestyle. The results provide evidence that the integrated model successfully 
Table 6. Analysis of interaction terms

\begin{tabular}{|l|l|l|l|l|l|l|}
\hline & \multicolumn{2}{|c|}{ PLS-SEM } & \multicolumn{2}{c|}{ PLSc } & \multicolumn{2}{c|}{ CB-SEM } \\
\hline & \multicolumn{1}{|c|}{$\begin{array}{c}\text { Path } \\
\text { coefficient }\end{array}$} & p-value & \multicolumn{1}{|c|}{$\begin{array}{c}\text { Path } \\
\text { coefficient }\end{array}$} & p-value & \multicolumn{1}{c|}{$\begin{array}{c}\text { Path } \\
\text { coefficient }\end{array}$} & p-value \\
\hline HIO $\rightarrow$ eHBI & 0.263 & 0.000 & 0.287 & 0.000 & 0.424 & 0.000 \\
\hline NSI $\rightarrow$ eHBI & 0.051 & 0.038 & 0.064 & 0.044 & 0.026 & 0.053 \\
\hline HIO*NSI $\rightarrow$ eHBI & -0.042 & 0.038 & -0.053 & 0.054 & -0.007 & 0.601 \\
\hline ATeH $\rightarrow$ eHL & 0.538 & 0.000 & 0.600 & 0.000 & 0.636 & 0.000 \\
\hline NSI $\rightarrow$ eHL & -0.003 & 0.906 & -0.005 & 0.812 & -0.004 & 0.681 \\
\hline Ateh* NSI $\rightarrow$ eHL & 0.042 & 0.244 & 0.047 & 0.178 & 0.020 & 0.051 \\
\hline
\end{tabular}

NSI: Need for Online Social Interaction

explains the learning process and essential driving factors that affect 18-30-year-old adults' eHealth Behavioral Intention.

This model provides a foundation and allows future modification that can extend the research target to other population groups. The validated model also has substantial practical implications for health information professionals, eHealth educators, and health practitioners. The efforts to understand the online health-related behavior of 18-30-year-old college students and to provide them health management and disease prevention information can be fostered by using online health information channels. As discussed above, 18-30-year-old adults learn new behaviors through the process of reinforcement of rewards and punishments. Rewarding the experience of using a new behavior can enhance the beliefs of users about it and elevate users' competencies of using the new behavior. As a result, users are more likely to adjust their actions to the new behaviors. The results also indicate that a cognitive factor (Attitude toward eHealth) contributes to enhancing one's skills in finding, understanding and appropriately applying health information (eHealth Literacy), which in turn, leads to greater Behavioral Intention to adopt eHealth.

This study also provides important practical implications. For example, health practitioners and educators can add text or video tutorials to their website to introduce information about health management, methods to prevent disease or treatment options to potential eHealth users. Gaining more knowledge and confidence in using the Internet as a venue as an efficient health resource would lead to higher intention to use. In addition, the results show that Need for Online Social Interaction significantly moderates the relationship between Attitude toward eHealth and eHealth Literacy, as well as the relationship between Health Information Orientation and eHealth Behavioral Intention at the significance level of 0.10. In other words, social factors such as the Need for Online Social Interaction could enhance eHealth Behavioral Intention among young adult users. Thus, the results suggest that online health practitioners can create virtual communities or online groups to encourage health-oriented social support and interactions among online users. Moreover, healthcare providers or health educators can utilize the Internet and social media sites such as Facebook, Twitter, and YouTube to develop and motivate Online Health Behavior, Health Information Orientation, and eHealth Literacy. These developments can improve eHealth Behavioral Intention.

The findings also contribute to the SEM literature. Contradicting Astrachan et al.'s (2014) study, in which one hypothesis is rejected using CB-SEM while it is accepted using PLS-SEM, this study shows consistent hypothesis testing results when using either PLS-SEM or CB-SEM. The results are more reliable because this study addresses all limitations such as one-item construct and a comparison of different model structures in Astrachan et al.'s work. The findings partially contradict Gelhard and Delft's (2016) study, which underestimated the use of PLSc. Although PLSc's path coefficients are not significantly different from corresponding PLS's results, the results show significant improvement 
by comparing the number of significant path coefficients between PLS vs. CB-SEM, and PLSc vs. CB-SEM in Table 5. In addition, all R square values of PLS and PLSc are significantly different. Thus, compared to traditional PLS, PLSc made important corrections in terms of path estimates and variance explained coefficients. The values of most PLSc's path coefficients and all PLSc's R squares are in-between the corresponding values of PLS and CB. This finding supports Dijkstra's (2010) work, which indicated that the values of correlations between latent variables and the $\mathrm{R}^{2} \mathrm{~s}$ of endogenous constructs are underestimated in the conventional PLS-SEM approach. Dijkstra's (2014) PLSc successfully handled the PLS's consistency issues with respect to both path and variance explained coefficients.

Despite the expected difference in coefficient results, both methods provide similar results with respect to hypothesis testing, which is often the main goal of a study. Thus, as supported in Hair et al. (2011), the use of PLSc, PLS-SEM or CB-SEM should also depend on research goals. If the goal is exploratory or predicting key driving factors in a model, PLSc and PLS-SEM should be considered. In contrast, if the goal is theory testing or confirmation, CB-SEM should be used. If the purpose of a study is to find the coefficient values to measure the strength of the relationship between latent variables, PLSc or CB-SEM should be used since they produce results that are more consistent.

According to the results of the goodness of fit indices, all three SEM methods provide good model fit indices. This study is the first to compare the SRMR and NFI indices of the PLS and PLSc methods with other CB-SEM fit indices in an eHealth context. Although the use of fit indices to assess the overall model fit has not been discussed in-depth in PLS-SEM literature, the findings support the consistency between PLSc and PLS-SEM's SRMR or NFI indices and other fit indices in CB-SEM. This study recommends the use of these indices because of the benefit and the consistency in the results provided by the three SEM approaches.

Hair et al.'s (2017) study inspired us to extend the comparison of PLS and CB-SEM in a more complex model in which interaction terms are included. With the appearance of interaction terms, the results from SEM methods are no longer consistent. The Need for Online Social Interaction is statistically supported by the CB-SEM method to increase the strength of the relationship between Attitude toward eHealth and eHealth Literacy but is not supported by the PLS and the PLSc methods. Similarly, the impact of Need for Online Social Interaction on the relationship between Health Information Orientation and eHealth Behavioral Intention is supported by PLS and PLSc, but not by the CB-SEM method. Thus, this study cannot provide any reliable conclusion based on these inconsistent results.

\section{FUTURE RESEARCH AND CONCLUSION}

This study develops and tests a new eHealth model that identifies the main antecedents of eHealth Behavioral Intention, including Health Information Orientation, Online Health Behavior, and eHealth Literacy. The findings add value to both existing eHealth literature and healthcare practices. Although the findings are promising, several limitations exist in this work. The diverse sample of college students covers a broad and essential subset of 18-30-year-old adults in general. However, the authors are aware that 18-30-year-old college students might not be representative of the population of 18-30-year-old eHealth users. Accordingly, as with most studies, a larger and broader population will be needed to consider the generalizability of the results. The use of online health information and services is a voluntary action. The findings might not cover a mandatory use required by specific eHealth environment (e.g., an EHR is required for an issued e-Prescription). Thus, it leaves a room for future research to improve this study.

The study investigates the perceptions of respondents about Internet sources in general. It means that, besides the reliable information from well-recognized sources such as CDC, National Institutes of Health $(\mathrm{NIH})$, government healthcare sites, or $\mathrm{NIH}$, the sources may include many unreliable websites or social media sites providing misinformation. The analysis of participants' perceptions 
shows that $71.8 \%, 65.4 \%, 65.5 \%$, and $61.9 \%$ of the respondents are likely to care about the accuracy of information, the credibility of the author, the currency of information, and the citation for information, respectively. In addition, a prior research (Prybutok \& Ryan, 2015) found that a similar group of respondents was likely to use the first source that is provided to an online search, which also raises a question about how well the users are screening the sources for credibility. This is not a claim that the respondents do not care about the quality of the information because the results indicate that they are likely to have concerns but does raise a concern about their diligence in screening. Thus, it is necessary for healthcare providers and educators to remind users about the importance of reliable sources and the plethora of misinformation available on the Internet. Future research is suggested that focuses on the specific types of internet sources as well as how to identify simple/uninformed sites versus more credible healthcare provider platforms.

The proposed model provides an overview of eHealth behavioral intention and is potentially applicable to similar or varied population groups in other developed or developing countries. Understanding the eHealth behavior of 18-30-year-olds is key to improving personal health management, providing easier access to health information and preventing the increase of negative health behaviors such as vaping, use of marijuana, opiate or other drug use, and activities that result in STDs. The proposed model emphasizes the power of eHealth and provides public health administrators and educators with a valuable and accessible tool to help change health behaviors of young people ages 18-30 years.

This research performs and compares the use of PLS-SEM, PLSc, and CB-SEM methods on an eHealth model using a similar dataset. The findings of these different methods provide consistent results for hypothesis testing and coefficient determination $\mathrm{R}^{2}$. Again, these findings contradicted the results in Astrachan et al.'s (2014) study. By addressing all the problems of Astrachan et al.'s model designs, the results support the use of all three SEM approaches for hypothesis testing purposes in reflective models. In addition, this study is the first to investigate CB-SEM's global fit indices and recently developed PLS's and PLSc's fit indices. The results of SRMR and NFI retrieved from the PLS-SEM and PLSc approaches are relatively consistent with other fit indices provided by CB-SEM. The tested results empirically support the use of SRMR, NFI, and other PLS's potential fit indices in future research. The findings recommend that PLS and PLSc users should not depend only on these overall fit indices to evaluate a model without considering other factors such as path coefficient, $\mathrm{R}^{2}$, and theory.

The findings support the guidelines proposed by Sarstedt et al. (2016) that CB-SEM is recommended for use with models with only reflective constructs. However, these findings recommend the use of PLSc over PLS, when CB-SEM's matrix results are not definite. The CBSEM's convergence issue occurs often when the model is too complex or the sample size is too small. In some healthcare-related studies, like interviewing people living with HIV, a small sample size is common and understandable but is still very valuable. In these cases, PLS and PLSc should be considered. The findings in the current research support the validity of PLS and PLSc SEM techniques and hopefully discourages their arbitrary avoidance. In contrast to the finding of Gelhard and Delft's (2016) study, this study finds the significant difference between the results of PLS's and PLSc's path estimates and R squares. According to the results, PLSc significantly outperforms PLS with respect to the consistency of path coefficient estimates in reflective models. This result directly supports the finding in Dijkstra and Henseler's (2015) study and as such provides some clarification about the findings of Gelhard and Delft's (2016) research. In short, the findings emphasize the model and data specific relationships associated with the choice of a methodology.

The coefficient results produced by CB-SEM, PLS, and PLSc are no longer consistent with interaction-term path coefficient estimates. The use of SEM on models with interaction terms has not been well developed in the literature. This study shows the importance of conducting future research that clarifies which SEM method provides more reliable interaction term estimates. This study compares the use of CB-SEM, PLS, and PLSc on a model within reflective constructs. Future research 
may include other composite-based SEM approaches such as Generalized Structured Component Analysis (Hwang, 2009). In addition, future research can extend the comparison on formative measurement models because PLS-SEM can handle models with both formative and reflective constructs, while CB-SEM has limitations in handling formative measures without appropriate model specifications (Dolce \& Lauro, 2015). 


\section{REFERENCES}

Ajzen, I. (1985). From intentions to actions: A theory of planned behavior. Action Control, 11-39. Retrieved from http://www-unix.oit.umass.edu/?aizen

Ajzen, I., \& Fishbein, M. (1980). Understanding attitudes and predicting social behavior. Englewood Cliffs, NJ: Prentice-Hall.

Astrachan, C. B., Patel, V. K., \& Wanzenried, G. (2014). A comparative study of CB-SEM and PLS-SEM for theory development in family firm research. Journal of Family Business Strategy, 5(1), 116-128. doi:10.1016/j. jfbs.2013.12.002

Atkin, C. (1973). Instrumental utilities and information seeking. In New Models for Mass Communication Research (pp. 205-242). Sage.

Atkin, C. (1985). Informational utility and selective exposure. In D. Zillman \& J. Bryant (Eds.), Selective Exposure to Communication. Routledge.

Bandura, A. (1969). Social-Learning Theory Of Identificatory Processes. In Handbook of Socialization Theory and Research (pp. 213-262). doi:10.1080/19371918.2011.591629

Bandura, A. (1986). Social foundations of thought and action: A social cognitive theory. Social Foundations of Thought and Action: A Social Cognitive Theory. Englewood Cliffs, NJ: Prentice-Hall, Inc.

Bandura, A. (1988). Organisational applications of social cognitive theory. Australian Journal of Management, 13(2), 275-302. doi:10.1177/031289628801300210

Bandura, A. (1998). Health promotion from the perspective of social cognitive theory. Psychology \& Health, 13(4), 623-649. doi:10.1080/08870449808407422

Chartrand, T. L., \& Bargh, J. A. (1999). The chameleon effect: The perception-behavior link and social interaction. Journal of Personality and Social Psychology, 76(6), 893-910. doi:10.1037/0022-3514.76.6.893 PMID:10402679

Cho, J., Park, D., \& Lee, E. (2014). Cognitive Factors of Using Health Apps: Systematic Analysis of Relationships Among Health Consciousness, Health Information Orientation, eHealth Literacy, and Health App Use Efficacy. Journal of Medical Internet Research, 16(5), 125. doi:10.2196/jmir.3283 PMID:24824062

Cronbach, L. J. (1951). Coefficient alpha and the internal structure of tests. Psychometrika, 16(3), 297-334. doi:10.1007/BF02310555

Dijkstra, T. K. (2010). Latent variables and indices: Herman Wold's basic design and partial least squares. Handbook of Partial Least Squares, 23-46.

Dijkstra, T. K. (2014). PLS' Janus Face - Response to Professor Rigdon's "Rethinking Partial Least Squares Modeling: In Praise of Simple Methods." Long Range Planning, 47(3), 146-153. doi:10.1016/j.lrp.2014.02.004

Dijkstra, T. K., \& Henseler, J. (2015). Consistent Partial Least Squares Path Modeling. Management Information Systems Quarterly, 39(2), 297-316. doi:10.25300/MISQ/2015/39.2.02

Dolce, P., \& Lauro, N. C. (2015). Comparing maximum likelihood and PLS estimates for structural equation modeling with formative blocks. Quality \& Quantity, 49(3), 891-902. doi:10.1007/s11135-014-0106-8

Dutta-Bergman, M. (2003). Trusted Online Sources of Health Information: Differences in Demographics, Health Beliefs, and Health-Information Orientation. Journal of Medical Internet Research, 5(3), e21. doi:10.2196/ jmir.5.3.e21 PMID:14517112

Eng, T. R., Gustafson, D. H., Henderson, J., Jimison, H., \& Patrick, K. (1999). Introduction to evaluation of interactive health communication applications. American Journal of Preventive Medicine, 16(1), 10-15. doi:10.1016/S0749-3797(98)00107-X PMID:9894549

Erdelez, S. (1999). Information encountering: It's more than just bumping into information. Bulletin of the Association for Information Science and Technology, 26-29. 
Escoffery, C., Miner, K. R., Adame, D. D., Butler, S., Mccormick, L., \& Mendell, E. (2005). Internet use for health information among college students. Journal of American College Health, 8481. doi:10.3200/JACH.53.4.183188 PMID: 15663067

Fishbein, M., \& Ajzen, I. (1977). Belief, attitude, intention and behavior: An introduction to theory and research. Addison-Wesley.

Fornell, C., \& Larcker, D. F. (1981). Evaluating Structural Equation Models with Unobservable Variables and Measurement Error. JMR, Journal of Marketing Research, 18(1), 39-50. doi:10.1177/002224378101800104

Gelhard, C., \& Von Delft, S. (2016). The role of organizational capabilities in achieving superior sustainability performance. Journal of Business Research, 69(10), 4632-4642. doi:10.1016/j.jbusres.2016.03.053

Godin, G., \& Kok, G. (1996). The Theory of Planned Behavior: A Review of Its Applications to HealthRelated Behaviors. American Journal of Health Promotion, 11(2), 87-98. doi:10.4278/0890-1171-11.2.87 PMID:10163601

Guide, V. D. R., \& Ketokivi, M. (2015). Notes from the Editors: Redefining some methodological criteria for the journal. Journal of Operations Management, 37, v-viii. doi:10.1016/S0272-6963(15)00056-X

Hair, J. F., Hult, G. T. M., Ringle, C. M., \& Sarstedt, M. (2016). A primer on partial least squares structural equation modeling (PLS-SEM). Sage Publications.

Hair, J. F., Hult, G. T. M., Ringle, C. M., Sarstedt, M., \& Thiele, K. O. (2017). Mirror, mirror on the wall: A comparative evaluation of composite-based structural equation modeling methods. Journal of the Academy of Marketing Science. doi:10.1007/s11747-017-0517-x

Hair, J. F., Ringle, C. M., \& Sarstedt, M. (2011). PLS-SEM: Indeed a Silver Bullet. Journal of Marketing Theory and Practice, 19(2), 139-152. doi:10.2753/MTP1069-6679190202

Han, J. Y., Kim, J. H., Yoon, H. J., Shim, M., McTavish, F. M., \& Gustafson, D. H. (2012). Social and psychological determinants of levels of engagement with an online breast cancer support group: Posters, lurkers, and nonusers. Journal of Health Communication, 17(3), 356-371. doi:10.1080/10810730.2011.585696 PMID:22085215

Haridakis, P., \& Hanson, G. (2009). Social interaction and co-viewing with YouTube: Blending mass communication reception and social connection. Journal of Broadcasting \& Electronic Media, 53(2), 317-335. doi: $10.1080 / 08838150902908270$

Hsieh, P.-J. (2016). An empirical investigation of patients' acceptance and resistance toward the health cloud: The dual factor perspective. Computers in Human Behavior, 63, 959-969. doi:10.1016/j.chb.2016.06.029

Hu, Y., \& Shyam Sundar, S. (2010). Effects of Online Health Sources on Credibility and Behavioral Intentions. Communication Research, 37(1), 105-132. doi:10.1177/0093650209351512

Hwang, H. (2009). Generalized structured component analysis. Psychometrika, 74(3), 517-530. doi:10.1007/ s11336-009-9119-y

Jones, C. M. (2013). Heroin use and heroin use risk behaviors among nonmedical users of prescription opioid pain relievers - United States, 2002-2004 and 2008-2010. Drug and Alcohol Dependence, 132(1-2), 95-100. doi:10.1016/j.drugalcdep.2013.01.007 PMID:23410617

Jöreskog, K. G. (1973). A general method for estimating a linear structural equation system. ETS Research Bulletin Series, (2), i-41. doi:10.1002/j.2333-8504.1970.tb00783.x

Kelly, B. J., Niederdeppe, J., \& Hornik, R. C. (2009). Validating measures of scanned information exposure in the context of cancer prevention and screening behaviors. Journal of Health Communication, 14(8), 721-740. doi:10.1080/10810730903295559 PMID:20029707

Kim, S., \& Yoon, J. (2012). The use of an online forum for health information by married Korean women in the United States. Information Research, 17(2), 1.

Lankenau, S. E., Teti, M., Silva, K., Bloom, J. J., Harocopos, A., \& Treese, M. (2012). Initiation into prescription opioid misuse amongst young injection drug users. The International Journal on Drug Policy, 23(1), 37-44. doi:10.1016/j.drugpo.2011.05.014 PMID:21689917 
Liu, Y. (2010). Social media tools as a learning resource. Journal of Educational Technology Development and Exchange, 3(1), 101-114. doi:10.18785/jetde.0301.08

Macleod, J., Oakes, R., Copello, A., Crome, I., Egger, M., Hickman, M., \& Davey Smith, G. et al. (2004). Psychological and social sequelae of cannabis and other illicit drug use by young people: A systematic review of longitudinal, general population studies. Lancet, 363(9421), 1579-1588. doi:10.1016/S0140-6736(04)16200-4 PMID:15145631

Marton, C. (2003). Quality of health information on the Web: User perceptions of relevance and reliability. The New Review of Information Behaviour Research, 4(1), 195-206. doi:10.1080/14716310310001631525

McCabe, S. E., Teter, C. J., Boyd, C. J., Knight, J. R., \& Wechsler, H. (2005). Nonmedical use of prescription opioids among U.S. college students: Prevalence and correlates from a national survey. Addictive Behaviors, 30(4), 789-805. doi:10.1016/j.addbeh.2004.08.024 PMID:15833582

McMillen, R. C., Gottlieb, M. A., Whitmore Shaefer, R. M., Winickoff, J. P., \& Klein, J. D. (2015). Trends in electronic cigarette use among U.S. adults: Use is increasing in both smokers and nonsmokers. Nicotine \& Tobacco Research, 17(10), 1195-1202. doi:10.1093/ntr/ntu213 PMID:25381306

Moorman, C., \& Matulich, E. (1993). A Model of Consumers' Preventive Health Behaviors: The Role of Health Motivation and Health Ability. The Journal of Consumer Research, 20(2), 208. doi:10.1086/209344

Noh, H. I., Lee, J. M., Yun, Y. H., Park, S. Y., Bae, D. S., Nam, J. H., ... \& Chang, Y. J. (2009). Cervical cancer patient information-seeking behaviors, information needs, and information sources in South Korea. Cervical Cancer Patient Information-Seeking Behaviors, Information Needs, and Information Sources in South Korea, 17(10), 1277-1283. doi:10.1007/s00520-009-0581-y PMID:19172301

Norman, C. D., \& Skinner, H. A. (2006). eHEALS: The eHealth Literacy Scale. Journal of Medical Internet Research, 8(4), e27. doi:10.2196/jmir.8.4.e27 PMID:17213046

Nunnally, J. C., \& Bernstein, I. H. (1994). The theory of measurement error. In Psychometric Theory (pp. 209-247).

Olkin, I., \& Finn, J. D. (1995). Correlations redux. Psychological Bulletin, 118(1), 155-164. doi:10.1037/00332909.118.1.155

Paek, H.-J., \& Hove, T. (2012). Social Cognitive Factors and Perceived Social Influences That Improve Adolescent eHealth Literacy. Health Communication, 27(8), 727-737. doi:10.1080/10410236.2011.616627 PMID:22452551

Pew Research Center. (2017). Share of adults in the United States who use the internet in 2016, by age group. Retrieved from https://www.statista.com/statistics/266587/percentage-of-internet-users-by-age-groups-in-the-us/

Prybutok, G. (2013). Youtube: An effective web 2.0 informing channel for health education to prevent stds. Informing Science: The International Journal of an Emerging Transdiscipline, 16(1), 19-36. doi:10.28945/1773

Prybutok, G., Harun, A., \& Prybutok, V. (2017). EHealth marketing to millennials: A view through a systemigram. International Journal of Electronic Healthcare, 9(4), 319. doi:10.1504/IJEH.2017.085823

Prybutok, G. L. (2014). An integrative model of eHealth communication: a study of 18-30 year old college students [Doctoral Dissertation]. University of North Texas.

Prybutok, G. L., Koh, C., \& Prybutok, V. R. (2014). A content relevance model for social media health information. Computers, Informatics, Nursing, 32(4), 189-200. doi:10.1097/CIN.0000000000000041 PMID:24429836

Prybutok, G., \& Ryan, S. (2015). Social Media: The Key to Health Information Access for 18- to 30-Year-Old College Students. Computers, Informatics, Nursing, 33(4), 132-141. doi:10.1097/CIN.0000000000000147 PMID:25887107

Richards, H., King, G., Reid, M., Selvaraj, S., McNicol, I., Brebner, E., \& Godden, D. (2005). Remote working: Survey of attitudes to eHealth of doctors and nurses in rural general practices in the United Kingdom. Family Practice, 22(1), 2-7. doi:10.1093/fampra/cmh716 PMID:15642724

Ringle, C. M., Sarstedt, M., \& Straub, D. (2012). A critical look at the use of PLS-SEM in MIS Quarterly. Management Information Systems Quarterly, 36(1), iii-xiv. doi:10.2307/41410402 
Ronkko, M., \& Evermann, J. (2013). A critical examination of common beliefs about partial least squares path modeling. Organizational Research Methods, 16(3), 425-448. doi:10.1177/1094428112474693

Rönkkö, M., McIntosh, C. N., Antonakis, J., \& Edwards, J. R. (2016). Partial least squares path modeling: Time for some serious second thoughts. Journal of Operations Management, 47-48(1), 9-27. doi:10.1016/j. jom.2016.05.002

Sarstedt, M., Hair, J. F., Ringle, C. M., Thiele, K. O., \& Gudergan, S. P. (2016). Estimation issues with PLS and CBSEM: Where the bias lies! Journal of Business Research, 69(10), 3998-4010. doi:10.1016/j. jbusres.2016.06.007

Suggs, L. S. (2006). A 10-year retrospective of research in new technologies for health communication. Journal of Health Communication, 11(1), 61-74. doi:10.1080/10810730500461083 PMID:16546919

The Health Communicator's Social Media Toolkit. (2011). Centers for Disease Control and Prevention. Retrieved from http://www.cdc.gov/SocialMedia/Tools/guidelines/

Unger, J. B., Soto, D. W., \& Leventhal, A. (2016). E-cigarette use and subsequent cigarette and marijuana use among Hispanic young adults. Drug and Alcohol Dependence, 163, 261-264. doi:10.1016/j.drugalcdep.2016.04.027 PMID:27141841

Weaver, J. B. III, Mays, D., Weaver, S. S., Hopkins, G. L., Eroglu, D., \& Bernhardt, J. M. (2010). Health information-seeking behaviors, health indicators, and health risks. American Journal of Public Health, 100(8), 1520-1525. doi:10.2105/AJPH.2009.180521 PMID:20558794

Werts, C. E., Linn, R. L., \& Jöreskog, K. G. (1974). Intraclass reliability estimates: Testing structural assumption. Educational and Psychological Measurement, 33(509), 25-33. doi:10.1177/001316447403400104

WHO. (2016). Global Diffusion of eHealth: Making universal health coverage achievable.

WHO. (2017). eHealth at WHO.

WHO. (2018). Global health workforce shortage to reach 12.9 million in coming decades. Retrieved from http:// www.who.int/mediacentre/news/releases/2013/health-workforce-shortage/en/

Wold, H. (1974). Causal flows with latent variables: partings of the ways in the light of NIPALS modelling. European Economic Review. Retrieved from http://www.sciencedirect.com/science/article/pii/0014292174900087

Yi, M. Y., Yoon, J. J., Davis, J. M., \& Lee, T. (2013). Untangling the antecedents of initial trust in Web-based health information: The roles of argument quality, source expertise, and user perceptions of information quality and risk. Decision Support Systems, 55(1), 284-295. doi:10.1016/j.dss.2013.01.029

Zhang, X., Guo, X., Wu, Y., Lai, K.-H., \& Vogel, D. (2017). Exploring the inhibitors of online health service use intention: A status quo bias perspective. Information \& Management, 54(8), 987-997. doi:10.1016/j. im.2017.02.001

Zibbell, J. E., Iqbal, K., Patel, R. C., Suryaprasad, A., Sanders, K. J., Moore-Moravian, L., \& Holtzman, D. et al. (2015). Increases in hepatitis $C$ virus infection related to injection drug use among persons aged $<=30$ years-Kentucky, Tennessee, Virginia, and West Virginia, 2006-2012. Morbidity and Mortality; Weekly Report, 64(17), 453-458. PMID:25950251 